\title{
Clinical form of asthma and vaccine immunity in preschoolers
}

\author{
Anna Bednarek ${ }^{1}$, Anna Bodajko-Grochowska², Robert Klepacz³, Katarzyna Szczekala4, Danuta Zarzycka1 , Andrzej Emeryk ${ }^{2}$
}

${ }^{1}$ Department of Pediatric Nursing, Medical University of Lublin, Lublin, Poland

2Department of Pulmonary Diseases and Children Rheumatology, Medical University of Lublin, Lublin, Poland

${ }^{3}$ Department of Clinical Pathomorphology, Medical University of Lublin, Lublin, Poland

${ }^{4}$ Interfaculty Centre for Didactics, Department of Foreign Languages, Medical University of Lublin, Lublin, Poland

Adv Dermatol Allergol 2021; XXXVIII (1): 123-130

DOI: https://doi.org/10.5114/ada.2021.104287

\begin{abstract}
Introduction: Asthma is the most common chronic disease in children. Its exacerbation results from allergic and infectious diseases.

Aim: To assess the influence of a clinical form of asthma on preschoolers' vaccine immunity following 3 years after the completion of the mandatory vaccination programme.

Material and methods: The study encompassed 172 preschool children with asthma being newly diagnosed, including 140 patients with mild asthma and 32 with moderate asthma, whose vaccine immunity (level of IgG-specific antibodies) was assessed after the mandatory early vaccines had been administered in the early childhood. Monovalent vaccines (HBV + IPV + Hib) along with a three-component combined vaccine (DTwP) and MMR were given to 86 children while a six-component combined vaccine (DTaP + IPV + Hib + HBV) along with a three-component MMR vaccine were administered to the remaining 86 children. The immunity class for particular vaccinations was assessed according to the manufacturers' instructions.

Results: Children suffering from mild asthma had considerably more frequently vaccinations administered on time ( $p<0.001)$ and the type of vaccines (monovalent or highly-combined) administered did not have a significant influence on the clinical form of asthma in the children examined $(p=0.6951)$. Apart from the vaccines against hepatitis $B$ and rubella where considerably more frequently a high level of antibodies occurred in children with mild asthma, the antibody levels to other vaccines, namely diphtheria, tetanus, pertussis, Hib and mumps, were not associated with the severity of asthma.
\end{abstract}

Conclusions: Moderate asthma may have a negative impact on remote vaccine immunity to HBV and rubella.

Key words: asthma, children, vaccine immunity.

\section{Introduction}

Asthma is the most common chronic respiratory disease in children. The results of prospective studies indicate that episodes of bronchial obturation occur in $30 \%$ of children aged up to 3 years old and in $50 \%$ of patients up to 12 years old $[1,2]$.

Diagnosing asthma is particularly difficult in young children because of non-specific symptoms and the occurrence of many diseases that mask asthma. For this age group, there are no standardised tests assessing the respiratory tract in terms of inflammation or obturation present. The basis for asthma diagnosis in children $<5$ years old is clinical assessment by means of the Asthma Predictive Index (API) and effectiveness of the therapeutic attempt with a low dose of glucocorticosteroids (GCS) and the exclusion of other causes of obturation [3-6].

The most common cause of exacerbation of asthma in children is a respiratory disease, mainly of viral aetiology $[7,8]$. In the light of the GINA 2012 guidelines, the classification of asthma based on its severity (intermittent asthma, mild persistent asthma, moderate persistent asthma and severe persistent asthma) is of great

Address for correspondence: Anna Bednarek, Department of Pediatric Nursing, Medical University of Lublin, University Children' Hospital, 6 Professor Antoni Gębala St, 20-093 Lublin, Poland, phone: +48 44877 40, +48 607607 115, e-mail: bednarekanna@o2.pl Received: 23.07.2018, accepted: 9.08.2019. 
practical significance and is useful during the initial assessment of a patient who has not been treated with drugs controlling the symptoms to make a therapeutic decision [9-12].

A typical form of early paediatric asthma is characterised by, prior to the proper diagnosis, long-lasting infections (> 10 days) or affecting the lower respiratory tract each time causing bronchitis or pneumonia. The course of an infection can be feverish or unfeverish. Recurrent respiratory tract infections (RTIs) are usually manifestations of allergic changes. They hinder protective vaccination of young children resulting in frequent and significant delays in the administration of successive doses of rudimentary and supplementary vaccinations [13-15].

In Poland, over $96 \%$ of parents have their children vaccinated, including roughly a half of them choosing modern and highly-combined vaccines. The greatest number of obligatory vaccinations are performed during the first 2 years of children. At the time, they are usually given a full scheme of rudimentary vaccine doses against different infectious diseases [16].

\section{Aim}

The aim of the work is the assessment of the influence of a clinical form of asthma on vaccine immunity in children after the completion of a full and rudimentary programme of obligatory vaccinations.

\section{Material and methods}

The research was carried out on 178 preschool children (mean age: $5.22 \pm 0.34$ ) with newly diagnosed asthma (lgE-dependent) who were hospitalised in the Clinic of Lung Diseases and Paediatric Rheumatology of the Children's University Hospital in Lublin (Poland). Three groups of patients were distinguished depending on the severity of the disease: mild, moderate and severe. Then, coverage of obligatory vaccinations was analysed. Finally, 172 children were qualified for the study, including 140 patients with a mild clinical form of the disease and 32 with moderate asthma, whose vaccine immunity (level of a specific antibody of IgG class) was analysed after the completion of obligatory vaccinations in early childhood (from birth to the age of $2-2.5$ years old). Two children were excluded from the study due to lack of documents that could confirm the accomplishment of the full cycle of obligatory vaccinations and four children with severe asthma (a low number).

In 86 children, obligatory vaccinations were done by means of non-combined vaccines, namely monovalent HBV vaccine (recombined vaccine), poliomyelitis vaccine (IPV - Inactivated Poliomyelitis Vaccine), Haemophilus influenzae type $b$ (Hib) vaccine (conjugate and adsorbed) and a three-component combined vaccine against diphtheria, tetanus and pertussis (DTPw - whole-celled) as well as a three-component MMR vaccine against measles, mumps and rubella. The children studied had been administered with three doses of rudimentary HBV, DTPW or DTPa, Hib vaccines and two doses of IPV and one dose of MMR. Moreover, they were given the fourth dose of the rudimentary booster against DTPW, Hib and the third booster of IPV.

The remaining 86 children were vaccinated with six-component combined bacterial and viral vaccine, Infanrix hexa of the cycle of 3 rudimentary doses and one booster, against HBV (recombined), poliomyelitis (IPV, Inactivated Poliomyelitis Vaccine), Hib - Haemophilus influenzae type b (conjugate and adsorbed), diphtheria, tetanus, pertussis (with acellular component $\mathrm{Pa}$ ). A threecomponent combined vaccine against measles, mumps, rubella (MMR) was used only once.

The research was carried out from 2014 to 2015 after it had been approved by the Bioethics Committee of the Medical University of Lublin (No. KE-0254/176/2011) and after consent had been obtained from the parents of the hospitalised children studied.

\section{Characteristics of children with asthma}

The analysis encompassed 172 preschoolers (mean age: $5.22 \pm 0.34$ years old) with newly diagnosed asthma, roughly $56 \%$ of them constituted boys, the remaining $44 \%$ girls. The diagnosis of asthma in the children was made based on a modified version of the Asthma Predictive Index (API) recommended by the Global Initiative for Asthma (GINA) 2012 for children under 5 years of age. Consistent with the API algorithm, the study included children with $\geq 4$ episodes of obturation lasting at least $24 \mathrm{~h}$, including $\geq 1$ confirmed by a physician and at least one major risk factor (asthma running in parents, atopic dermatitis, allergic reactions to inhaled allergens) or two minor ones (bronchial obturation independent of an infection, eosinophilia of above $4 \%$, allergic reactions to food allergens) [4, 9]. Moreover, the children experienced $>1$ episode of dyspnoea per month, higher frequency of wheezing on exhalation (on a scale from 1 "seldom" to 5 "most days" the parents marked at least 3) and paroxysmal and dry cough on exertion.

All the children examined did not suffer from other obstructive diseases such as cystic fibrosis, primary ciliary dyskinesia, congenital respiratory or circulatory defects, gastroesophageal reflux disease, severe combined immunodeficiency, tuberculosis, thoracic tumours, goiter, granuloma and infections by Bordetella Pertussis, Chlamydia trachomatis or atypical ones.

In the study group, treatment was instituted according to the current guidelines. Control asthma therapy was used with low doses of inhaled glucocorticosteroids (IGCS); 100-200 $\mu \mathrm{g}$ of Budesonide permanently and a drug widening the bronchi temporarily (SABA) with a pressurised metered-dose inhaler (pMDI) and aerochamber with a mouthpiece for children aged 4-6 years 
old. In the children, bronchial obstruction seldom subsided spontaneously and it always abated due to the treatment applied. Approximately 4\% of the patients studied required systemic GCs at the present time or in the past.

The condition of airways in the children was assessed by means of peak expiratory flow (PEF) measured with a peak flow meter, a hand-held device recommended for self-control of the disease. A changeability index of maximal exploratory flow was determined, which is the difference between morning and evening measurement, and the degree of severity as well as control of asthma were established. Children with mild asthma (140 of the patients) were identified in whom the disease was controlled appropriately (PEF changeability $<20 \%$ ) and those (32 of the patients) with moderate asthma that was partially controlled (PEF changeability 20-30\%). Examinations to assess allergy were also performed: a skin prick test, percentage of eosinophils and a level of total lgE in the peripheral blood was measured. An interview with the parents and analysis of hospital documents provided information on selected demographic features and family structure, type of nutrition during the first 6 months of the children's lives and their current state of health. A family history of allergic diseases and comorbidities of atopic diseases was also taken into account. In $7 \%$ of the patients, symptoms of atopic dermatitis were found and in $4 \%$ of the patients, allergic rhinitis was diagnosed.

No comorbidities or disorders of somatic and psychomotor development were diagnosed in the children. They came from two-parent families who cooperated in therapy and self-control of the disease. The data on their vaccination coverage, vaccination timetable and types of vaccine used were obtained from medical documents of the children (health certificate on vaccination) (Table 1).

\section{Serological analysis}

The children's blood specimens were collected to analyse antibodies concentration after the completion of the rudimentary cycle of obligatory vaccination on the second day of their hospital stay in the morning while performing other routine examinations. The children were fasting. A total of $4.9 \mathrm{ml}$ of blood was taken by means of the S-Monovette ${ }^{\circledast}$ system with clotting activator (Sarstedt, Nümbrecht, Germany). Then, the blood was centrifuged at $300 \mathrm{~g}$ speed for $10 \mathrm{~min}$ at $4^{\circ} \mathrm{C}$. The sera obtained were collected into $1.5-\mathrm{ml}$ polyethylene Eppendorf test tubes and stored frozen at $-20^{\circ} \mathrm{C}$ until the analysis. None of the samples showed a trace of haemolysis. The examination was carried out using the Victor 3 Plate Reader from Perkin Elmer at the Chair and Department of Clinical Immunology at the Medical University of Lublin.

Following the administration of obligatory vaccines against diphtheria, tetanus, Hib, poliomyelitis, mumps, rubella and measles, the vaccine immunity assessment was conducted by the ELISA immunoenzymatic method.
Certified tests of IBL International GmbH, Hamburg, were applied to assess the antibodies concentration of IgG class.

The level of HBV antibodies was measured chemiluminescently with the ADVIA Centaur XP Immunoassay System in the Laboratory of Medical Analyses ALAB in Poland. Similar analyses were carried out to check the level of immunoglobulin IgE total in the blood serum of the children with asthma. The concentration of selenium was measured by Mass Spectroscopy method (ICP-MS) using the X-Series 2 ICP-MS from Thermo Scientific in the Laboratory of Medical Analyses ALAB in Germany. The level of calcium in the children's blood serum was determined by the colorimetric method (with Arsenazo III dye) using the ADVIA 1800 in the Laboratory of Medical Analyses ALAB in Poland.

\section{Statistical analysis}

Statistical characteristics of continuous variables are shown as arithmetic means and their standard deviations (SDs). Normal distribution of continuous variables was verified with the Shapiro-Wilk test. The distribution type and statistical significance of intergroup differences were verified with the Student $t$-test or Mann-Whitney $U$-test. Distributions of discrete variables are presented as numbers and percentages; their intergroup comparisons were based on $\chi^{2}$ test and Fisher exact test. Connections between clinical forms of asthma and categorised concentration values of antibodies analysed were estimated based on odds ratio (OR). All calculations were carried out with Statistica 12 software package (StatSoft, Tulsa, OK, United States). The statistical significance threshold for all tests was set at $p<0.05$.

Table 1. General characteristics of the children with asthma

\begin{tabular}{llcc}
\hline Property & & $\mathbf{N}$ & $\%$ \\
\hline $\begin{array}{l}\text { Concomitant allergic } \\
\text { diseases }\end{array}$ & Atopic dermatitis & 12 & 6.97 \\
\cline { 2 - 4 } $\begin{array}{l}\text { Family history of } \\
\text { allergy }\end{array}$ & Yllergic rhinitis & 7 & 4.07 \\
\cline { 2 - 4 } & No & 104 & 60.46 \\
\hline Eosinophilia & $<5 \%$ & 68 & 39.53 \\
\cline { 2 - 4 } & $\geq 5 \%$ & 60 & 34.88 \\
\hline PEF changeability & $<20 \%$ & 112 & 65.12 \\
\cline { 2 - 4 } & $20-30 \%$ & 140 & 81.40 \\
\hline Asthma therapy & $\begin{array}{l}\text { Inhaled } \\
\text { glucocorticosteroids }\end{array}$ & 18.60 \\
\hline & (IGCs) & 100 \\
\cline { 2 - 4 } & $\begin{array}{l}\text { Short acting } \beta 2-m i m e t i c s \\
\text { (SABA) }\end{array}$ & 172 & 100 \\
\hline $\begin{array}{l}\text { Past systemic steroid } \\
\text { therapy }\end{array}$ & Yes & 166 & 96.51 \\
\cline { 2 - 4 } & No & & \\
\hline
\end{tabular}




\section{Results}

Statistically significant higher current weight was found in the children with a mild clinical form of asthma (Table 2).

As far as statistical significance is concerned, none of the remaining demographic and medical interview properties analysed among the children with asthma was connected with clinical forms of asthma (Table 3).

The children with mild asthma had the prompt administration of vaccines significantly more frequently than the children with moderate asthma. The type of vaccines administered (monovalent of highly-combined) did change significantly the form of asthma in the group researched (Table 4).
Apart from HBV and rubella vaccinations, where statistically significant higher (protective) vaccine concentration values occurred more frequently in the children with mild asthma, concentration values after other vaccinations (diphtheria, tetanus, pertussis, Hib, mumps) were not associated with a clinical form of asthma. Protective concentration values in the children with asthma were found in $100 \%$ after vaccination against poliomyelitis $(\geq 12 \mathrm{U} / \mathrm{ml})$ and measles $(\geq 300 \mathrm{ml} \mathrm{U} / \mathrm{ml})$.

The clinical form of asthma had no statistically significant connections with categorised concentration values against diphtheria, tetanus, pertussis, Hib and mumps. The OR values obtained explicitly show that moderate asthma is a risk factor for decreased vaccine immunity to HBV and rubella assessed based on IgG.

Table 2. Clinical forms of asthma and selected demographic parameters and medical interviews

\begin{tabular}{|c|c|c|c|c|c|c|}
\hline \multicolumn{2}{|l|}{ Parameters analysed } & \multicolumn{2}{|c|}{$\begin{array}{c}\text { Mild } \\
(N=140)\end{array}$} & \multicolumn{2}{|c|}{$\begin{array}{l}\text { Moderate } \\
(N=32)\end{array}$} & \multirow[t]{2}{*}{$P$-value } \\
\hline & & $n$ & $\%$ & $n$ & $\%$ & \\
\hline \multirow[t]{2}{*}{ Gender } & Boys & 76 & 54.29 & 20 & 62.5 & \multirow[t]{2}{*}{0.3986} \\
\hline & Girls & 64 & 45.71 & 12 & 37.5 & \\
\hline \multirow[t]{2}{*}{ Age } & & M & SD & M & SD & \multirow[t]{2}{*}{0.2914} \\
\hline & & 5.20 & 0.38 & 5.30 & 0.39 & \\
\hline \multicolumn{2}{|l|}{ Current body weight } & 20.80 & 3.77 & 19.10 & 4.76 & $<0.05$ \\
\hline \multicolumn{2}{|l|}{ Current height } & 118.80 & 4.93 & 117.20 & 6.47 & 0.1210 \\
\hline \multicolumn{2}{|l|}{ Level of calcium in blood serum } & 8.80 & 1.26 & 8.60 & 1.37 & 0.4817 \\
\hline \multicolumn{2}{|l|}{ Level of selenium in blood serum } & 61.90 & 13.92 & 60.20 & 17.13 & 0.6709 \\
\hline \multicolumn{2}{|c|}{ IgE total concentration in blood serum } & 180.60 & 131.27 & 139.20 & 113.69 & 0.2477 \\
\hline \multirow[t]{2}{*}{ Place of residence } & Urban areas & 97 & 69.29 & 25 & 78.13 & \multirow[t]{2}{*}{0.3205} \\
\hline & Rural areas & 43 & 30.71 & 7 & 21.88 & \\
\hline \multirow{3}{*}{$\begin{array}{l}\text { Type of nutrition at the age of } \\
0-6 \text { months old }\end{array}$} & Mixed & 19 & 13.57 & 2 & 6.25 & \multirow[t]{3}{*}{0.3347} \\
\hline & Breast milk & 87 & 62.14 & 19 & 59.38 & \\
\hline & Evaporated milk formula & 34 & 24.29 & 11 & 34.38 & \\
\hline \multirow{2}{*}{$\begin{array}{l}\text { Past infectious childhood } \\
\text { diseases* }^{*}\end{array}$} & No & 122 & 87.14 & 28 & 87.50 & \multirow[t]{2}{*}{0.6110} \\
\hline & Yes & 18 & 12.86 & 4 & 12.50 & \\
\hline \multirow[t]{2}{*}{ Birth order in family } & $>1$ & 101 & 72.14 & 20 & 62.50 & \multirow[t]{2}{*}{0.2812} \\
\hline & 1 & 39 & 27.86 & 12 & 37.50 & \\
\hline \multirow{2}{*}{$\begin{array}{l}\text { Antibiotic therapy during } \\
\text { hospital stay }\end{array}$} & No & 45 & 32.14 & 10 & 31.25 & \multirow[t]{2}{*}{0.9222} \\
\hline & Yes & 95 & 67.86 & 22 & 68.75 & \\
\hline \multirow{3}{*}{$\begin{array}{l}\text { Titres of skin prick tests to } \\
\text { airborne allergens }\end{array}$} & Major (wheal diameter > 6 mm) & 18 & 12.86 & 9 & 28.13 & \multirow[t]{3}{*}{0.0743} \\
\hline & Moderate (wheal diameter of 3-6 mm) & 37 & 26.43 & 5 & 15.63 & \\
\hline & Minor (wheal diameter < $3 \mathrm{~mm}$ ) & 85 & 60.71 & 18 & 56.25 & \\
\hline \multirow{3}{*}{$\begin{array}{l}\text { Titres of skin prick tests to } \\
\text { food allergens }\end{array}$} & Major (wheal diameter > 6 mm) & 21 & 15.00 & 3 & 9.38 & \multirow[t]{3}{*}{0.2556} \\
\hline & Moderate (wheal diameter of 3-6 mm) & 54 & 38.57 & 9 & 28.13 & \\
\hline & Minor (wheal diameter < 3 mm) & 65 & 46.43 & 20 & 62.50 & \\
\hline
\end{tabular}

*Chickenpox $(n=10)$, rotavirus infections $(n=8)$. 
Table 3. Clinical forms of asthma and vaccines administered

\begin{tabular}{|c|c|c|c|c|c|c|}
\hline \multirow[t]{2}{*}{ Parameters analysed } & & \multicolumn{2}{|c|}{$\begin{array}{c}\text { Mild } \\
(N=140)\end{array}$} & \multicolumn{2}{|c|}{$\begin{array}{l}\text { Moderate } \\
(N=32)\end{array}$} & \multirow[t]{2}{*}{$P$-value } \\
\hline & & $n$ & $\%$ & $n$ & $\%$ & \\
\hline \multirow[t]{2}{*}{ Type of vaccines administered } & Monovalent & 71 & 50.71 & 15 & 46.88 & \multirow[t]{2}{*}{0.6951} \\
\hline & Highly-combined & 69 & 49.29 & 17 & 53.13 & \\
\hline \multirow{2}{*}{$\begin{array}{l}\text { Administration of vaccination according to the prescribed } \\
\text { schedule }\end{array}$} & No & 28 & 20.00 & 27 & 84.38 & \multirow[t]{2}{*}{$<0.001$} \\
\hline & Yes & 112 & 80.00 & 5 & 15.63 & \\
\hline
\end{tabular}

Table 4. Clinical forms of asthma and vaccine immunity

\begin{tabular}{|c|c|c|c|c|c|c|c|c|c|c|}
\hline \multicolumn{3}{|c|}{ Post-vaccination } & \multicolumn{2}{|c|}{$\begin{array}{c}\text { Mild } \\
(N=140)\end{array}$} & \multicolumn{2}{|c|}{$\begin{array}{c}\text { Moderate } \\
(N=32)\end{array}$} & \multirow[t]{2}{*}{$P$-value } & \multirow[t]{2}{*}{ OR } & \multicolumn{2}{|c|}{$95 \% \mathrm{Cl}$} \\
\hline Antibody & Concentration & Protecting level & $n$ & $\%$ & $n$ & $\%$ & & & & \\
\hline \multirow[t]{2}{*}{ HBV } & $>12.5 \mathrm{ml} \mathrm{U} / \mathrm{ml}$ & Yes & 122 & 87.14 & 11 & 34.38 & $<0.001$ & 12.94 & 5.36 & 31.24 \\
\hline & $<12.5 \mathrm{ml} \mathrm{U} / \mathrm{ml}$ & No & 18 & 12.86 & 21 & 65.63 & & & & \\
\hline \multirow[t]{2}{*}{ Diphtheria } & $\geq 1 \mathrm{IU} / \mathrm{ml}$ & Yes & 66 & 47.14 & 20 & 62.50 & 0.1170 & 0.54 & 0.24 & 1.18 \\
\hline & $<1 \mathrm{IU} / \mathrm{ml}$ & No & 74 & 52.86 & 12 & 37.50 & & & & \\
\hline \multirow[t]{2}{*}{ Tetanus } & $\geq 1 \mathrm{IU} / \mathrm{ml}$ & Yes & 98 & 70.00 & 24 & 75.00 & 0.5741 & 0.78 & 0.32 & 1.87 \\
\hline & $<1 \mathrm{IU} / \mathrm{ml}$ & No & 42 & 30.00 & 8 & 25.00 & & & & \\
\hline \multirow[t]{2}{*}{ Pertussis } & $\geq 10 \mathrm{U} / \mathrm{ml}$ & Yes & 113 & 80.71 & 26 & 81.25 & 0.9446 & 1.04 & 0.39 & 2.76 \\
\hline & $<10 \mathrm{U} / \mathrm{ml}$ & No & 27 & 19.29 & 6 & 18.75 & & & & \\
\hline \multirow[t]{2}{*}{$\mathrm{Hib}$} & $\geq 1 \mu \mathrm{g} / \mathrm{ml}$ & Yes & 123 & 87.86 & 27 & 84.38 & 0.3890 & 1.34 & 0.45 & 3.95 \\
\hline & $<1 \mu \mathrm{g} / \mathrm{ml}$ & No & 17 & 12.14 & 5 & 15.63 & & & & \\
\hline \multirow[t]{2}{*}{ Mumps } & $\geq 12 \mathrm{U} / \mathrm{ml}$ & Yes & 117 & 83.57 & 23 & 71.88 & 0.1250 & 1.99 & 0.82 & 4.85 \\
\hline & $<12 \mathrm{U} / \mathrm{ml}$ & No & 23 & 16.43 & 9 & 28.13 & & & & \\
\hline \multirow[t]{2}{*}{ Rubella } & $\geq 12 \mathrm{IU} / \mathrm{ml}$ & Yes & 130 & 92.86 & 26 & 81.25 & $<0.05$ & 3.00 & 1.00 & 8.98 \\
\hline & $<12 \mathrm{IU} / \mathrm{ml}$ & No & 10 & 7.14 & 6 & 18.75 & & & & \\
\hline
\end{tabular}

*Values of concentration values indicating vaccine immunity presented in particular measure units were assumed according to the manufacturers' recom

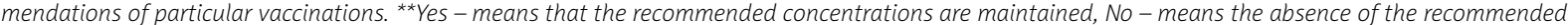
concentrations.

\section{Discussion}

A cause of symptomology of paediatric asthma, different from adult one, is anatomical and physiological differences in the respiratory and immune systems [17, 18]. Many publications indicate that being male is a risk factor for asthma development. A more common occurrence of asthma in boys is explained by the narrower bronchi and greater bronchial hyperresponsiveness to a bronchospasm due to nonspecific stimuli [19-21].

Epidemiological data indicate that mild asthma occurs in over $70 \%$ of children. Approximately $25 \%$ of children suffer from moderate asthma. The severest form of asthma is diagnosed in $3 \%$ of children $[22,23]$. Current GINA guidelines stress their main role of IGCs in therapy of each form of asthma in children. All the children taking part in our research were treated with IGCS regardless of severity of their clinical form of asthma [10].

Infants and preschool children often suffer from recurrent bronchial symptoms such as wheezing and cough caused by lower respiratory tract infections. Newborns and infants run a particular risk of getting an infection because their immune system is not fully developed yet. Although transferring maternal antibodies by the placenta provides protection against pathogens, potential antigen burden is very high in comparison with the relatively sterile environment of the uterus. After birth, infants are said to have immune tolerance that guarantees protection after being exposed to different pathogens in the environment of development and adaptation to external conditions [24, 25].

Viral respiratory infections are the most common cause of bronchial obstructive diseases in children. The research reveals that children who underwent viral bronchiolitis or other forms of respiratory infections manifested by wheezing at the age of $2-3$ years old have a higher risk of asthma [26-28]. However, being ill with some infections or administering vaccines, proved among other things on the example of tuberculosis vaccination, can 
also play a role of an adjuvant in initiating a profile of immune response with a majority of Th1-dependent cytokines, hence decreasing the significance of T2 population, which can result in a preventive role of asthma occurrence $[13,18,29]$.

The influence of an infection on asthma is not entirely explicit $[2,5,30]$. Little is known about the influence of asthma on declined humoral immunity even after the administration of protective vaccines. The research shows that children with asthma had an increased risk of chickenpox in comparison with children not suffering from asthma (adjusted OR of 1.63, 95\% Cl: 1.04-2.55, $p<0.05)$. Therefore, as research authors suggest a history of asthma can be an unrecognised risk factor for chickenpox [31]. Simultaneously, developing bronchial hyperresponsiveness and a majority of Th2-dependent response are associated with a decline in measles antibodies in children and this influence takes place prior to the occurrence of clinical asthma symptoms. Therefore, disappearance of antibodies against measles can be an essential unrecognised immune property of asthma. The research results of that issue require further investigation and confirmation [30].

Commonly breastfeeding is thought to be a factor positively affecting the development and differentiation of pulmonary parenchyma that leads to an increase in parameters of pulmonary volume and flow values. Therefore, exclusive breastfeeding for 4-6 months after birth seems to be justified as a preventive method of respiratory diseases, including asthma in childhood [17, 18]. In our study, most children with any clinical form of asthma were breastfed during the first 6 months of their lives.

A family history of asthma (in first-degree relatives) constitutes a risk factor for allergic diseases, including asthma [3]. In our study, for both clinical forms of asthma, the vast majority of the children ran a family history of allergy and was not the first child in the family. In over a half of the children researched, the results of skin prick tests to airborne and food allergens were negative (wheal diameter $<3 \mathrm{~mm}$ ) for both clinical forms of asthma. This indicates that the main factor aggravating the course of disease is respiratory infections, which has been confirmed in many studies [5].

Selenium (Se) plays a dominant role in many processes such as modulation of the immune system by antiviral activity and improvement of humoral immunity response. Some scientific reports suggest that Se insufficiency can affect immune disorders regarding both humoral and cellular responses. The results of present studies show that the administration of selenium nanoparticle (SeNP) to mice increased Th1 immune response and caused the production of cytokines. This immune profile clearly showed that selenium has an ability of polarisation of the immune system in the direction of Th1 model and thus increases efficacy of vaccines against many viral and bacterial pathogens specifically controlled by cellular immune responses [32]. In the study by Garcia et al. [33], the average concentration of selenium was significantly lower in patients with measles than in the control group $(46.4 \pm 14.1 \mu \mathrm{g} / \mathrm{l}$ vs. $86.5 \pm 13.9 \mu \mathrm{g} / \mathrm{l} ; p<0.0001)$. However, it was not associated with age, gender, vaccination coverage, clinical symptoms and specific antibody titre. Levels of selenium did not differ considerably between patients with uncomplicated measles $(45.8 \pm 14.2 \mathrm{\mu g} / \mathrm{l})$ and patients suffering from measles with complications $(52.7 \pm 13.2 \mu \mathrm{g} / \mathrm{l} ; p=0.15)$. Authors concluded that a clinical course of measles was associated with a substantial decrease in selenium that did not affect the risk of measles complications, though. This suggests the presence of compensating mechanisms against the diseases in those patients.

Calcium has a multi-directional influence on the immune system, predominantly due to the release of inflammatory mediators from basophiles and activation of T lymphocytes via calcine urines, diminishes permeability of the respiratory system mucous membranes for pathogens and significantly influences the proper process of cell division in immune cells of the cardiovascular system (lymphocytes and granulocytes) [14, 19]. In our research, both selenium concentration (23-114 $\mu \mathrm{g} / \mathrm{l}$ for children aged 5 years old) and calcium concentration (8.4-10.4 $\mathrm{mg} / \mathrm{dl}$ for individuals aged $1-18$ years old) as well as total lgE in blood serum (0.4-351.6 IU/ml for children aged 1-4 years old and $0.5-393 \mathrm{lU} / \mathrm{ml}$ for children aged 5-10 years old) did not diversify the clinical forms of asthma analysed and comprised the ranges of clinical standards for the age.

As far as vaccine immunity presented in this work is concerned, it refers to the time around 3 years after the completion of all rudimentary vaccinations and for both clinical forms of asthma it did not diversify significantly antibody titres for most vaccinations, i.e. against diphtheria, tetanus, pertussis, poliomyelitis, haemophilus influenzae type $b$, measles and mumps. However, a clinical form of asthma was statistically significant in terms of connections with vaccine immunity to HBV and rubella because it was diminished in children with a moderate clinical form of asthma. Similar findings were observed in works by Yoo et al. [34] where authors examined vaccine immunity to rubella, assessed based on IgG in teenagers vaccinated with two doses of MMR vaccine. The research was carried out in children with asthma, healthy ones and those from a group of high risk of developing asthma. The research results show that the children with asthma had a considerably lower immune response both humoral one (healthy children: $52.7 \pm 52.3$ SD; risk group children: $47.8 \pm 30.7$ SD; children with asthma: $37.4 \pm 25.9$ SD) and cellular one (healthy children: $1.23 \pm 1.08$ SD; risk group children: $1.42 \pm 1.32 \mathrm{SD}$; children with asthma: 0.64 $\pm 1.23 \mathrm{SD}$ ) to vaccinations against rubella in comparison with healthy children and those from a risk group. On the other hand, research by the same author from 2010 [35] 
confirmed solely lower titres of cellular response against rubella and mumps in children with asthma in comparison with healthy children. But no differences were found in levels of antibodies IgG to antigens of those viruses. Thus, those authors suggest that this situation in children with asthma can be caused by non-optimal predisposition dependent on cells of immune response to vaccine viruses of MMR that is modified by family factors [25]. Other conclusions were drawn by Masten et al. [36] who assessed vaccine immunity to HBV in children with asthma and in healthy ones. In both of the groups, the level of specific antibodies and profile of pro-inflammatory cytokines released by lymphocytes were analysed. Except for the anti-HBV IgE level, no differences were noted in the concentration of the parameters examined (IgG1, IgG2, IgG3, IgA, IgM anti-Hep B and IFN- $\gamma$ lymphocytes, IL-4 and IL-5) in children with asthma and healthy ones.

Exacerbation of clinical symptoms in moderate persistent asthma is slightly greater than in mild one, which becomes a risk factor for respiratory infections that most frequently are characterized by a longer course with changeability of clinical symptoms. In consequence, protective vaccinations are delayed, which, in turn, leads to, sometimes a considerable shift in a schedule of successive doses in the rudimentary or supplementary cycle. This suggests a possible influence on the lack of protective value of vaccine antibodies in children with chronic diseases, including asthma. Scarce research indicates that the issue concerns predominantly children with severe asthma in whom vaccine immunity is obtained in $80 \%$ only whereas children with mild or moderate asthma obtained response to vaccination against influenza in $100 \%$ [37].

Our study which focused on vaccine immunity in children with asthma and being dependent on a clinical form of asthma, assessed around 3 years after the accomplishment of the entire rudimentary protective vaccinations indicates the maintenance of protective antibody value after vaccinating against bacterial pathogens. However, the vaccine immunity turns out to be significantly different in children with moderate asthma after vaccinating against viruses (inactivated HBV and attenuated rubella vaccines). Due to little research into the relationship between vaccine immunity and clinical forms of asthma, the results obtained in this study require further investigation and verification.

\section{Conclusions}

Moderate asthma may have a negative impact on remote vaccine immunity to $\mathrm{HBV}$ and rubella.

\section{Conflict of interest}

The authors declare no conflict of interest.

\section{References}

1. Bateman ED, Hurd SS, Barnes PJ, et al. Global strategy for asthma management and prevention: GINA executive summary. Eur Respir J 2008; 31: 143-78.

2. Monica J, Federico MD, Heather E, et al. Asthma management for children risk identification and prevention. Adv Pediatr 2016; 63: 103-26.

3. Bisgaard H, Szefler S. Prevalence of asthma-like symptoms in young children. Pediatr Pulmonol 2007; 42: 723-8.

4. Castro-Rodriguez JA, Holberg CJ, Wright AL, et al. A clinical index to define risk of asthma in young children with recurrent wheezing. Am J Respir Crit Care Med 2000; 162: 1403-6.

5. Juhn YJ. Risks for infection in patients with asthma (or other atopic conditions): is asthma more than a chronic airway disease? J Allergy Clin Immunol 2014; 134: 247-57.

6. Hagan JB, Samant SA, Volcheck GW, et al. The risk of asthma exacerbation after reducing inhaled corticosteroids: a systemic review and meta-analysis of randomized controlled trials. Allergy 2014; 69: 510-6.

7. Yagiyeva N, Devereux G, Fielding S, et al. Outcomes of childhood asthma and wheezy bronchitis - a 50-year cohort study. Am J Respir Crit Care Med 2016; 193: 23-30.

8. Akinbami LJ, Moorman JE, Simon AE, et al. Trends in racial disparities for asthma outcomes among children 0 to 17 years, 2001-2010. J Allergy Clin Immunol 2014; 134: 547-53.

9. From the Global Strategy for Asthma Management and Prevention, Global Initiative for Asthma (GINA) 2012 [online]. [Access: 2013.08.05]. Available from: http://www.ginasthma. org/.

10. Global Initiative for Asthma (GINA): Global Strategy for Asthma Management and Prevention. WHO/NHLBI Workshop Report 2014.

11. Han MK, Agusti A, Calverley PM, et al. Chronic obstructive pulmonary disease phenotypes. The future of COPD. Am J Respir Crit Care Med 2010; 182: 598-604.

12. Chung KF, Wenzel SE, Brozek JL, et al. International ERS/ATS guidelines on definition, evaluation and treatment of severe asthma. Eur Respir 2014; 43: 343-73.

13. Brunst KJ, Ryan PH, Brokamp C, et al. Timing and duration of traffic-related air pollution exposure and the risk for childhood wheeze and asthma. Am J Respir Crit Care Med 2015; 192: 421-7.

14. Lezmi G, Gosset P, Deschildre A, et al. Airway remodeling in preschool children with severe recurrent wheeze. Am J Respir Crit Care Med 2015; 192: 164-71.

15. Boulet LP, FitzGerald JM, Reddel HK. The revised 2014 GINA strategy report: opportunities for change. Curr Opin Pulm Med 2015; 21: 1-7.

16. Mrożek-Budzyn D. The evolution of Polish Immunization Schedule during the last 10 years. Przegl Epidemiol 2012; 66: 107-12.

17. Sonnappa S, Bastardo CM, Saglani S, et al. Relationship between past airway pathology and current lung function in preschool wheezers. Eur Respir J 2011; 38: 1431-6.

18. Malmstrom K, Malmberg LP, O’Reilly R, et al. Lung function, airway remodeling and inflammation in infants: outcome at 8 years. Ann Allergy Asthma Immunol 2015; 114: 90-6.

19. Anderson WC III, Szefler SJ. New and future strategies to improve asthma control in children. J Allergy Clin Immunol 2015; 136: 848-59.

20. Matricardi PM, Illi S, Gruber C, et al. Wheezing in childhood: incidence, longitudinal patterns and factors predicting persistence. Eur Respir J 2008; 32: 585-92. 
21. Guilbert TW, Mauger DT, Lemanske RF. Childhood asthma - predictive phenotype. J Allergy Clin Immunol Pract 2014; 2: 664-70.

22. Lotvall J, Akdis CA, Bacharier LB, et al. Asthma endotypes: a new approach to classification of disease entities within the asthma syndrome. J Allergy Clin Immunol 2011; 127: 355-60.

23. Koczulla AR, Vogelmeier CF, Garn H, et al. New concepts in asthma: clinical phenotypes and pathophysiological mechanisms. Drug Discov Today 2017; 22: 388-96.

24. Caudri D, Savenije OE, Smit HA, et al. Perinatal risk factors for wheezing phenotypes in the first 8 years of life. Clin Exp Allergy 2013; 43: 1395-405.

25. Clare M, Lloyd SS. Development of allergic immunity in early life. Immunol Rev 2017; 278: 101-15.

26. Krishnamoorthy N, Khare A, Oriss TB, et al. Early infection with respiratory syncytial virus impairs regulatory $T$ cell function and increases susceptibility to allergic asthma. Nat Med 2012; 18: 1525-30.

27. Gollwitzer ES, Marsland BJ. Impact of early-life exposures on immune maturation and susceptibility to disease. Trends Immunol 2015; 36: 684-96.

28. O'Connor TG, Winter MA, Hunn J, et al. Prenatal maternal anxiety predicts reduced adaptive immunity in infants. Brain Behav Immun 2013; 32: 21-8.

29. Ege MJ, Mayer M, Normand AC, et al. Group GTS. Exposure to environmental microorganisms and childhood asthma. N Engl J Med 2011; 364: 701-9.

30. Timmermann CA, Osuna CE, Steuerwald U, et al. Asthma and allergy in children with and without prior measles, mumps, and rubella vaccination. Pediatr Allergy Immunol 2015; 26: 742-9.

31. Umaretiya PJ, Swanson JB, Kwon HJ, et al. Asthma and risk of breakthrough varicella infection in children. Allergy Asthma Proc 2016; 37: 207-15.

32. Mahdavi M, Mavandadnejad F, Yazdi MH, et al. Oral administration of synthetic selenium nanoparticles induced robust Th1 cytokine pattern after HBs antygen vaccination in mouse model. J Infect Public Health 2017; 10: 102-9.

33. Garcia M, Pineau A, Guillard O, et al. Low serum selenium concentrations in French patients with measles. Curr Res Transl Med 2017; 65: 89-91.

34. Yoo KH, Jacobson RM, Poland GA, et al. Asthma status and waning of measles antibody concentrations after measles immunization. Pediatr Infect Dis J 2014; 33: 1016-22.

35. Yoo KH, Agarwal K, Butterfield M, et al. Assessment of humoral and cell-mediated immune response to measlesmumps-rubella vaccine viruses among patients with asthma. Allergy Asthma Proc 2010; 31: 499-506.

36. Masten B, Lipscomb M, McWilliam B, et al. Immune response to Hepatitis B vaccine in asthmatic children. Pediatr Pulm 2003; 36: 522-8.

37. William W, Busse SP, Peters MJ, et al. Vaccination of patients with mild and severe asthma with a 2009 pandemic H1N1 influenza virus vaccine. J Allergy Clin Immunol 2011; 127: 130-7.e3. 